\title{
C/2013 R1 (LOVEJOY) AT IR WAVELENGTHS AND THE VARIABILITY OF CO ABUNDANCES AMONG OORT CLOUD COMETS
}

\author{
L. Paganini ${ }^{1,2}$, M. J. Mumma ${ }^{1}$, G. L. Villanueva ${ }^{1,2}$, J. V. Keane ${ }^{3,4}$, G. A. Blake ${ }^{5}$, B. P. Bonev ${ }^{1,2}$, \\ M. A. DiSanti ${ }^{1}$, E. L. GibB ${ }^{6}$, And K. J. MeECH ${ }^{3,4}$ \\ ${ }^{1}$ Goddard Center for Astrobiology, NASA GSFC, MS 690, Greenbelt, MD 20771, USA; lucas.paganini@ @asa.gov \\ ${ }^{2}$ Department of Physics, Catholic University of America, Washington, DC 20064, USA \\ ${ }^{3}$ Institute for Astronomy, University of Hawaii, Honolulu, HI 96822, USA \\ ${ }^{4}$ NASA Astrobiology Institute \\ ${ }^{5}$ Division of Geological and Planetary Sciences, California Institute of Technology, Pasadena, CA 91125, USA \\ ${ }^{6}$ Department of Physics and Astronomy, University of Missouri-St. Louis, St. Louis, MO 63121, USA \\ Received 2014 March 26; accepted 2014 June 30; published 2014 August 6
}

\begin{abstract}
We report production rates, rotational temperatures, and related parameters for gases in C/2013 R1 (Lovejoy) using the Near InfraRed SPECtrometer at the Keck Observatory, on six UT dates spanning heliocentric distances $\left(R_{h}\right)$ that decreased from 1.35 $\mathrm{AU}$ to $1.16 \mathrm{AU}$ (pre-perihelion). We quantified nine gaseous species $\left(\mathrm{H}_{2} \mathrm{O}, \mathrm{OH}^{*}, \mathrm{CO}\right.$, $\mathrm{CH}_{4}, \mathrm{HCN}, \mathrm{C}_{2} \mathrm{H}_{6}, \mathrm{CH}_{3} \mathrm{OH}, \mathrm{NH}_{3}$, and $\left.\mathrm{NH}_{2}\right)$ and obtained upper limits for two others $\left(\mathrm{C}_{2} \mathrm{H}_{2}\right.$ and $\left.\mathrm{H}_{2} \mathrm{CO}\right)$. Compared with organics-normal comets, our results reveal highly enriched $\mathrm{CO}$, (at most) slightly enriched $\mathrm{CH}_{3} \mathrm{OH}, \mathrm{C}_{2} \mathrm{H}_{6}$, and $\mathrm{HCN}$, and $\mathrm{CH}_{4}$ consistent with "normal", yet depleted, $\mathrm{NH}_{3}, \mathrm{C}_{2} \mathrm{H}_{2}$, and $\mathrm{H}_{2} \mathrm{CO}$. Rotational temperatures increased from $\sim 50 \mathrm{~K}$ to $\sim 70 \mathrm{~K}$ with decreasing $R_{h}$, following a power law in $R_{h}$ of $-2.0 \pm 0.2$, while the water production rate increased from 1.0 to $3.9 \times 10^{28}$ molecules s ${ }^{-1}$, following a power law in $R_{h}$ of $-4.7 \pm 0.9$. The ortho-para ratio for $\mathrm{H}_{2} \mathrm{O}$ was $3.01 \pm 0.49$, corresponding to spin temperatures $\left(T_{\text {spin }}\right) \geqslant 29 \mathrm{~K}$ (at the $1 \sigma$ level). The observed spatial profiles for these emissions showed complex structures, possibly tied to nucleus rotation, although the cadence of our observations limits any definitive conclusions. The retrieved $\mathrm{CO}$ abundance in Lovejoy is more than twice the median value for comets in our IR survey, suggesting this comet is enriched in CO. We discuss the enriched value for $\mathrm{CO}$ in comet $\mathrm{C} / 2013 \mathrm{R} 1$ in terms of the variability of $\mathrm{CO}$ among Oort Cloud comets.
\end{abstract}

Key words: astrochemistry - comets: general - comets: individual (C/2013 R1 (Lovejoy)) - infrared: planetary systems - molecular processes - Oort Cloud

Online-only material: color figures

\section{INTRODUCTION}

Gravitational collapse of dense cores in molecular clouds triggers the genesis of young stellar objects. During formation of the star, the circumstellar disk and envelope contain gas, ice, and dust that are the basic ingredients of planet formation (van Dishoeck \& Blake 1998; van Dishoeck \& Hogerheijde 1999; Evans et al. 2009; Bergin 2011). The gas clears within the first few million years, and dynamical processes transform the accretion disk through a "transitional" disk phase, ultimately leaving major planets and an extended debris disk composed of leftovers from the planetary formation process. Our Sun and planetary system experienced a similar process, and comets, asteroids, and trans-Neptunian objects are the surviving leftovers. Thus, studying the chemical composition of these bodies helps us interpret their origins, and active comets afford a means of accomplishing this through remote sensing.

We can now build comet taxonomies based on cosmogonic parameters (such as chemical composition, isotopic fractionation, and spin temperatures) of primary (typically referred to as "parent") volatiles released from the nucleus (e.g., BockeléeMorvan et al. 2004; Mumma \& Charnley 2011), of product species (e.g., A'Hearn et al. 1995; Fink 2009; Cochran et al. 2012), along with dust signatures such as crystallinity and mineralogy (e.g., Wooden et al. 1997; Zolensky et al. 2006; Ootsubo et al. 2007). Developing such taxonomies is a critical step toward testing the physicochemical conditions that prevailed during the formation of our solar system, some 4.6 billion years ago.

Indeed, the composition of cometary nuclei is key to understanding the formation and evolution of matter in the early solar system. Once formed and expelled to their current reservoirs - the Kuiper Belt (the ecliptic comets, or ECs, come from the scattered Kuiper disk) and the Oort Cloud (OC; source of the nearly isotropic comets, or NICs) — cometary nuclei remain relatively preserved from external alteration, although post-processing (Stern 2003) and additional erosional and evolutionary effects may provide possible sources of chemical modification.

IR spectroscopy is a powerful technique for building a chemical taxonomy of comets through detections of primary volatiles (i.e., native species stored originally as ices in the nucleus), such as $\mathrm{H}_{2} \mathrm{O}, \mathrm{CO}, \mathrm{CO}_{2}$, and other less abundant species. Recently, the Akari infrared survey of 18 comets (both ECs and NICs) emphasized the importance of $\mathrm{CO}_{2}$, by demonstrating its high abundance (second only to $\mathrm{H}_{2} \mathrm{O}$ ) in many comets (Ootsubo et al. 2012). Only a few high- $\mathrm{CO}_{2}$ comets were identified earlier (e.g., 103P/Hartley 2; Weaver et al. 1994; Crovisier et al. 1999).

Direct measurements of $\mathrm{CO}_{2}$ in the cometary coma are only possible from space (a limitation of ground-based observations due to strong corresponding $\mathrm{CO}_{2}$ absorption in the terrestrial atmosphere), yet ground-based IR spectroscopy can gather unique insights from a large inventory of several other (hyper) volatiles, including $\mathrm{CO}$. Comets rich in $\mathrm{CO}$ have been hypothesized since the early 20th century (e.g., Fowler 1910, 1912; Pluvinel \& Baldet 1911), based on strong emission from the comet-tail bands of ionized carbon monoxide $\left(\mathrm{CO}^{+}\right)$. However, detailed knowledge of the ionization and dissociation efficiencies of its possible precursors (e.g., $\mathrm{CO}, \mathrm{CO}_{2}, \mathrm{H}_{2} \mathrm{CO}$, etc.) is required in order to assess their contributions to the observed $\mathrm{CO}^{+}$. Lacking 
such details, quantitative measurements of $\mathrm{CO}$ (whether native or product) are highly uncertain based on the observed $\mathrm{CO}^{+}$ emissions.

Direct observations of neutral $\mathrm{CO}$ in multiple wavelength regimes (radio, infrared, and ultraviolet) have established a wide range for measured $\mathrm{CO}$ abundances (relative to $\mathrm{H}_{2} \mathrm{O}$ ), ranging from a few tenths of a percent to $\sim 30 \%$ (BockeléeMorvan et al. 2004; Mumma \& Charnley 2011; Feldman et al. 2004, and references therein). But the largest complexity when interpreting measurements of $\mathrm{CO}$ stems from its possible parent species (i.e., extended sources). For instance, $\mathrm{CO}$ is a principal product of $\mathrm{CO}_{2}$ dissociation, so comets rich in $\mathrm{CO}_{2}$ should also reveal a significant production rate for $\mathrm{CO}$ - this product $\mathrm{CO}$ is extended and its detection is strongly dependent on the instrumental field-of-view (FOV). Native and extended sources of CO are discussed by Bockelée-Morvan et al. (2004), Cottin \& Fray (2008), and Mumma \& Charnley (2011).

Prior to 2013, only six comets within $2.5 \mathrm{AU}$ of the Sun (where both $\mathrm{H}_{2} \mathrm{O}$ and $\mathrm{CO}$ are active) were identified as being enriched in native CO. These comets are C/1995 O1 (Hale-Bopp; DiSanti et al. 1999, 2001; Bockelée-Morvan et al. 2010), C/1996 B2 (Hyakutake; Mumma et al. 1996; Biver et al. 1999; DiSanti et al. 2003), C/1999 T1 (McNaught-Hartley; Mumma et al. 2003; Biver et al. 2006), C/2001 Q4 (NEAT; Lupu et al. 2007), C/2008 Q3 (Garradd; Ootsubo et al. 2012), and C/2009 P1 (Garradd; e.g., Paganini et al. 2012b; Feaga et al. 2013).

During late 2013, we confirmed a relatively high abundance of CO in C/2013 R1 (Lovejoy; hereafter C/2013 R1), supporting the existence of a probably sparse (yet growing) fraction of $\mathrm{CO}$-rich comets, especially if we consider the scarcity of $\mathrm{CO}$ in most comets observed by the Akari survey. Here, we present our recent IR observations of comet C/2013 R1 and discuss the results found during our six-night observing campaign.

\section{OBSERVATIONS}

Comet C/2013 R1 was discovered by Terry Lovejoy on UT 2013 September 7, at $R_{h}=1.98 \mathrm{AU}$ and geocentric distance $(\Delta) 1.93 \mathrm{AU}$, with an apparent magnitude of $\sim 15$. Its large eccentricity ( $e=0.998)$, original semi-major axis ( $a=$ $339.3 \mathrm{AU})$, Tisserand parameter $\left(T_{j}=0.500\right)$, and inclination to the ecliptic ( $i=64.04$ ) classify it as a nearly isotropic (longperiod) comet originating from the OC (Nakano 2013).

The significant activity and interesting coma features observed by amateur astronomers prompted our IR observations in 2013 mid-October, using the Near InfraRed SPECtrometer (NIRSPEC) at the $10 \mathrm{~m} \mathrm{W.} \mathrm{M.} \mathrm{Keck} \mathrm{Observatory} \mathrm{atop} \mathrm{Mauna}$ Kea, Hawaii. We observed comet C/2013 R1 on six dates spanning $R_{h}=1.35-1.16 \mathrm{AU}$ pre-perihelion (perihelion was at $0.81 \mathrm{AU}$ on 2013 December 22). Spectra were acquired in the usual four-step sequence (ABBA) with an integration time of $30 \mathrm{~s}$ (or $60 \mathrm{~s})$ per step, nodding the telescope along the $\left(0{ }^{\prime \prime} 432 \times\right.$ $24^{\prime \prime}$ ) slit by $12^{\prime \prime}$ between A- and B-beam positions (see DiSanti et al. 2001; Bonev 2005; Villanueva et al. 2011a; Paganini et al. 2012a for details).

\section{RESULTS}

We measured abundances for nine gaseous species in $\mathrm{C} / 2013$ $\mathrm{R} 1\left(\mathrm{H}_{2} \mathrm{O}, \mathrm{OH}^{*}, \mathrm{CO}, \mathrm{CH}_{4}, \mathrm{HCN}, \mathrm{C}_{2} \mathrm{H}_{6}, \mathrm{CH}_{3} \mathrm{OH}, \mathrm{NH}_{3}\right.$, and $\left.\mathrm{NH}_{2}\right)$ and obtained upper limits for two others $\left(\mathrm{C}_{2} \mathrm{H}_{2}\right.$ and $\left.\mathrm{H}_{2} \mathrm{CO}\right)$. A list of temperatures, production rates, abundances, and other pertinent information is given in Table 1; weighted mean mixing ratios (i.e., abundances relative to $\mathrm{H}_{2} \mathrm{O}$ ) are given in table note "d." We display selected emissions in Figures 1 and 2.

\subsection{Rotational Temperatures}

Near-IR spectroscopy is sensitive to molecular ro-vibrational transitions, and the ability to detect multiple emission lines grants an accurate determination of the molecular abundances in the coma. Sampling of each trace gas simultaneously with water (the most abundant ice in cometary nuclei) reveals its relative abundance ratio directly, and removes most sources of systematic error that are often introduced when measured separately. To accurately determine the production rate for each molecular species we need to establish its rotational temperature $\left(T_{\text {rot }}\right)$ with high precision. This is essential for characterizing correct rotational level populations. Once $T_{\text {rot }}$ is known, accurate production rates are determined using fluorescence models we developed for each species: $\mathrm{H}_{2} \mathrm{O}$ (Villanueva et al. 2012a), $\mathrm{OH}^{*}$ (Bonev et al. 2006), $\mathrm{C}_{2} \mathrm{H}_{6}$ (Villanueva et al. 2011b; Radeva et al. 2011), $\mathrm{CO}, \mathrm{C}_{2} \mathrm{H}_{2}$, and $\mathrm{CH}_{4}$ (Paganini et al. 2013; Villanueva et al. 2011a; Gibb et al. 2003), $\mathrm{NH}_{3}, \mathrm{HCN}$ (Villanueva et al. 2013; Lippi et al. 2013), $\mathrm{NH}_{2}$ (Kawakita \& Mumma 2011), $\mathrm{H}_{2} \mathrm{CO}$ (DiSanti et al. 2006), and $\mathrm{CH}_{3} \mathrm{OH}$ (Villanueva et al. 2012b; DiSanti et al. 2013).

From the observed molecular emission lines, we retrieved rotational temperatures $\left(T_{\text {rot }}\right)$ for six molecules $\left(\mathrm{H}_{2} \mathrm{O}, \mathrm{CO}\right.$, $\mathrm{CH}_{4}, \mathrm{HCN}, \mathrm{C}_{2} \mathrm{H}_{6}$, and $\left.\mathrm{CH}_{3} \mathrm{OH}\right)$. For species whose $T_{\text {rot }}$ could not be determined, e.g., due to insufficient lines, restricted energy range, and/or poor signal-to-noise ratio, we adopted a value based on the results of other simultaneously observed molecules in the coma. In support of this approach, all derived rotational temperatures were consistent (within the $1 \sigma-2 \sigma$ level) on each date, suggesting a common temperature among species in the inner coma, as we generally find for a given comet. Figure 3(A) shows a gradual (and expected) increase of rotational temperature (from $\sim 50 \mathrm{~K}$ to $\sim 70 \mathrm{~K}$ ) with decreasing $R_{h}$. The best-fit temperature variation followed a power law in $R_{h}$ of $-2.0\left(T_{\text {rot }}=T_{1 \mathrm{AU}} R_{h}^{-2.0 \pm 0.2}\right.$, with $T_{1 \mathrm{AU}}=(93 \pm$ 3 ) $\mathrm{K}$ representing the fitted value extrapolated to $R_{h}=1 \mathrm{AU}$; see Figure 3 ). Although our measurements sample a relatively small range of $R_{h}$, this power law is consistent with "typical" values for other comets (e.g., see Biver et al. 1997, 1999).

\subsection{Production Rates}

We performed observations of $\mathrm{H}_{2} \mathrm{O}, \mathrm{CH}_{4}, \mathrm{C}_{2} \mathrm{H}_{6}$, and $\mathrm{HCN}$ simultaneously on five nights spanning October 22-29, and also on November 7. The water production rate increased from $1.0 \times$ $10^{28}$ to $3.9 \times 10^{28}$ molecules $\mathrm{s}^{-1}$ during this interval. On each night the measurements were nearly continuous over a span of $1 \mathrm{hr}$. We used these data to assess the evolution of abundances with $R_{h}$ for these species.

Our best-fit results indicate a rather steep increase in water production with decreasing heliocentric distance $\left(Q_{\mathrm{H} 2 \mathrm{O}}=\right.$ $Q_{1 \mathrm{AU}} R_{h}^{-4.7 \pm 0.9}$, with $Q_{1 \mathrm{AU}}=(6.66 \pm 1.55) \times 10^{28} \mathrm{~s}^{-1}$; Figure $3(\mathrm{~B})$ ), which is somewhat steeper than the typical (insolation-limited) value $\left(R_{h}{ }^{-2}\right)$ often seen in comets (Biver et al. 1999). A steeper power law could be related to an increase in outgassing associated with (slow) nucleus rotation during this brief interval. Alternatively, the slope is strongly influenced by the data obtained on November 7 that could reflect a secular jump such as an outburst would trigger (cf. CBET 3710). Further inspection reveals a significant increase in production rates on October 25 compared to neighboring dates (see 
Table 1

Retrieved Molecular Parameters for Primary and Product Volatiles in Comet C/2013 R1 (Lovejoy) ${ }^{\mathrm{a}}$

\begin{tabular}{|c|c|c|c|c|c|}
\hline Species & $\begin{array}{c}v^{\mathrm{b}} \\
\left(\mathrm{cm}^{-1}\right)\end{array}$ & Lines & $\begin{array}{l}T_{\text {rot }} \\
(\mathrm{K})\end{array}$ & $\begin{array}{l}\text { Global } Q^{\mathrm{c}} \\
\left(10^{26} \mathrm{~s}^{-1}\right)\end{array}$ & $\begin{array}{c}\text { Abundance }^{\mathrm{d}} \\
\left(\% \text { Relative to } \mathrm{H}_{2} \mathrm{O}\right)\end{array}$ \\
\hline \multicolumn{6}{|c|}{2013 October 22} \\
\hline$\overline{\mathrm{H}_{2} \mathrm{O}}$ & 3428.04 & 18 & $49_{-8}^{+11}$ & $185.4 \pm 19.2$ & 100 \\
\hline $\mathrm{CH}_{4}$ & 3041.70 & 5 & $54_{-6}^{+7}$ & $1.54 \pm 0.14$ & $0.68 \pm 0.12$ \\
\hline $\mathrm{C}_{2} \mathrm{H}_{6}$ & 2983.46 & 8 & $55_{-5}^{+7}$ & $1.38 \pm 0.17$ & $0.72 \pm 0.09$ \\
\hline $\mathrm{CH}_{3} \mathrm{OH}$ & 2850.53 & 17 & $46_{-4}^{+6}$ & $5.40 \pm 0.49$ & $2.75 \pm 0.38$ \\
\hline $\mathrm{HCN}$ & 3312.15 & 6 & $(50)^{\mathrm{f}}$ & $0.59 \pm 0.12$ & $0.32 \pm 0.07$ \\
\hline $\mathrm{NH}_{3}$ & 3295.41 & 1 & $(50)^{\mathrm{f}}$ & $<3.44$ & $<1.86$ \\
\hline $\mathrm{NH}_{2}$ & 3301.86 & 2 & $(50)^{\mathrm{f}}$ & $<0.35$ & $<0.19$ \\
\hline $\mathrm{C}_{2} \mathrm{H}_{2}$ & 3295.96 & 6 & $(50)^{\mathrm{f}}$ & $<0.92$ & $<0.50$ \\
\hline $\mathrm{H}_{2} \mathrm{CO}$ & 2780.97 & 12 & $(50)^{\mathrm{f}}$ & $<0.49$ & $<0.26$ \\
\hline \multicolumn{6}{|c|}{$\begin{array}{l}2013 \text { October } 24 \\
{ }^{\mathrm{e}} R_{h}=1.34 \mathrm{AU} ; \Delta\end{array}$} \\
\hline $\mathrm{H}_{2} \mathrm{O}$ & 2073.75 & 4 & $(50)^{f}$ & $153.2 \pm 25.2$ & 100 \\
\hline $\mathrm{CO}$ & 2143.12 & 6 & $47 \pm 3$ & $15.15 \pm 1.85$ & $9.89 \pm 2.03$ \\
\hline \multicolumn{6}{|c|}{$\begin{array}{l}2013 \text { October } 25 \\
{ }^{\mathrm{e}} R_{h}=1.33 \mathrm{AU} ; \Delta\end{array}$} \\
\hline $\mathrm{H}_{2} \mathrm{O}$ & 3442.05 & 12 & $55 \pm 10$ & $231.8 \pm 33.1$ & 100 \\
\hline $\mathrm{CH}_{4}$ & 3041.66 & 3 & $63_{-5}^{+1}$ & $2.87 \pm 0.17$ & $1.24 \pm 0.19$ \\
\hline $\mathrm{C}_{2} \mathrm{H}_{6}$ & 2904.94 & 9 & $(50)^{\mathrm{f}}$ & $2.17 \pm 0.35$ & $0.94 \pm 0.20$ \\
\hline $\mathrm{HCN}$ & 3313.65 & 10 & $54_{-7}^{+8}$ & $0.68 \pm 0.06$ & $0.29 \pm 0.05$ \\
\hline $\mathrm{NH}_{3}$ & 3315.17 & 2 & $(50)^{f}$ & $<2.54$ & $<1.09$ \\
\hline $\mathrm{NH}_{2}$ & 3301.86 & 2 & $(50)^{f}$ & $<0.22$ & $<0.10$ \\
\hline $\mathrm{C}_{2} \mathrm{H}_{2}$ & 3299.44 & 6 & $(50)^{\mathrm{f}}$ & $<0.15$ & $<0.07$ \\
\hline $\mathrm{H}_{2} \mathrm{CO}$ & 2779.99 & 12 & $(50)^{f}$ & $<0.34$ & $<0.15$ \\
\hline \multirow{2}{*}{\multicolumn{6}{|c|}{$\begin{array}{l}2013 \text { October } 27 \\
{ }^{\mathrm{e}} R_{h}=1.30 \mathrm{AU} ; \Delta\end{array}$}} \\
\hline & & & & & \\
\hline $\mathrm{H}_{2} \mathrm{O}$ & 3446.17 & 9 & $62 \pm 15$ & $155.6 \pm 24.9$ & 100 \\
\hline $\mathrm{CH}_{4}$ & 3041.66 & 3 & $63_{-6}^{+7}$ & $1.81 \pm 0.25$ & $1.16 \pm 0.25$ \\
\hline $\mathrm{C}_{2} \mathrm{H}_{6}$ & 2908.57 & 4 & $(60)^{f}$ & $1.74 \pm 0.37$ & $1.12 \pm 0.30$ \\
\hline $\mathrm{HCN}$ & 3305.63 & 9 & $(60)^{f}$ & $0.36 \pm 0.10$ & $0.23 \pm 0.07$ \\
\hline $\mathrm{NH}_{3}$ & 3306.30 & 2 & $(60)^{f}$ & $<0.36$ & $<0.23$ \\
\hline $\mathrm{NH}_{2}$ & 3304.94 & 3 & $(60)^{f}$ & $<0.29$ & $<0.19$ \\
\hline $\mathrm{C}_{2} \mathrm{H}_{2}$ & 3296.59 & 7 & $(60)^{f}$ & $<0.22$ & $<0.14$ \\
\hline $\mathrm{H}_{2} \mathrm{CO}$ & 2777.33 & 15 & $(60)^{f}$ & $<0.30$ & $<0.19$ \\
\hline \multirow{2}{*}{\multicolumn{6}{|c|}{$\begin{array}{l}2013 \text { October } 29 \\
{ }^{\mathrm{e}} R_{h}=1.28 \mathrm{AU} ; \Delta\end{array}$}} \\
\hline & & & & & \\
\hline$\overline{\mathrm{H}_{2} \mathrm{O}}$ & 3440.70 & 13 & $59_{-6}^{+3}$ & $145.0 \pm 40.9$ & 100 \\
\hline $\mathrm{CH}_{4}$ & 3048.09 & 5 & $63_{-3}^{+4}$ & $1.81 \pm 0.21$ & $1.25 \pm 0.38$ \\
\hline $\mathrm{C}_{2} \mathrm{H}_{6}$ & 2908.10 & 7 & $(60)^{f}$ & $1.08 \pm 0.25$ & $0.75 \pm 0.27$ \\
\hline $\mathrm{HCN}$ & 3307.94 & 10 & $56 \pm 5$ & $0.47 \pm 0.06$ & $0.32 \pm 0.10$ \\
\hline $\mathrm{NH}_{3}$ & 3306.25 & 2 & $(60)^{\mathrm{f}}$ & $<0.36$ & $<0.25$ \\
\hline $\mathrm{NH}_{2}$ & 3302.60 & 4 & $(60)^{f}$ & $<0.33$ & $<0.22$ \\
\hline $\mathrm{C}_{2} \mathrm{H}_{2}$ & 3298.44 & 4 & $(60)^{f}$ & $<0.17$ & $<0.12$ \\
\hline $\mathrm{H}_{2} \mathrm{CO}$ & 2779.17 & 13 & $(60)^{f}$ & $<0.28$ & $<0.19$ \\
\hline \multicolumn{6}{|c|}{$\begin{array}{l}2013 \text { November } 7 \\
{ }^{\mathrm{e}} R_{h}=1.16 \mathrm{AU} ; \Delta\end{array}$} \\
\hline $\mathrm{H}_{2} \mathrm{O}$ & 3450.15 & 9 & $70 \pm 2$ & $367.9 \pm 25.8$ & 100 \\
\hline $\mathrm{CH}_{4}$ & 3048.09 & 5 & $61 \pm 4$ & $3.35 \pm 0.25$ & $0.91 \pm 0.09$ \\
\hline $\mathrm{C}_{2} \mathrm{H}_{6}$ & 2907.58 & 10 & $72_{-10}^{+12}$ & $2.18 \pm 0.25$ & $0.59 \pm 0.08$ \\
\hline $\mathrm{HCN}$ & 3312.74 & 12 & $70_{-9}^{+11}$ & $0.87 \pm 0.07$ & $0.24 \pm 0.03$ \\
\hline $\mathrm{NH}_{3}$ & 3295.36 & 1 & $(70)^{\mathrm{f}}$ & $0.36 \pm 0.05$ & $0.10 \pm 0.02$ \\
\hline $\mathrm{NH}_{2}$ & 3304.99 & 3 & $(70)^{\mathrm{f}}$ & $0.44 \pm 0.26$ & $0.12 \pm 0.07$ \\
\hline $\mathrm{C}_{2} \mathrm{H}_{2}$ & 3305.13 & 6 & $(70)^{\mathrm{f}}$ & $<0.16$ & $<0.12$ \\
\hline $\mathrm{H}_{2} \mathrm{CO}$ & 2779.77 & 8 & $(70)^{f}$ & $<0.23$ & $<0.06$ \\
\hline
\end{tabular}

Notes.

${ }^{a}$ Uncertainties represent $1 \sigma$, and upper limits represent $3 \sigma$. The reported error in production rate includes the line-by-line scatter in measured column densities, along with photon noise, systematic uncertainty in the removal of the cometary continuum, and (minor) uncertainty in rotational temperature.

${ }^{\mathrm{b}}$ Mean wavenumber of all emission lines (used for this reduction) from a particular species.

${ }^{\mathrm{c}}$ Global production rate, after applying a measured growth factor to compensate slit losses.

${ }^{d}$ We also estimated the weighted mean relative abundance (\%) for each species: $\mathrm{CO}(9.89 \pm 2.03), \mathrm{CH}_{3} \mathrm{OH}(2.75 \pm 0.38), \mathrm{CH}_{4}(0.91 \pm 0.06), \mathrm{C}_{2} \mathrm{H}_{6}$ $(0.69 \pm 0.06), \mathrm{HCN}(0.26 \pm 0.02), \mathrm{NH}_{3}(0.10 \pm 0.02), \mathrm{NH}_{2}(0.12 \pm 0.07), \mathrm{C}_{2} \mathrm{H}_{2}(<0.07)$, and $\mathrm{H}_{2} \mathrm{CO}(<0.06)$.

${ }^{\mathrm{e}} R_{h}$ : heliocentric distance; $\Delta$ : geocentric distance; $\Delta$-dot: geocentric velocity; P.A.: position angle of the extended Sun-comet vector; $\alpha$ : solar phase (Sun-comet-Earth) angle. These values represent the mid-point of data acquisition. KL1, KL2, M-wide refer to standard NIRSPEC settings.

${ }^{\mathrm{f}}$ Assumed value based on retrieval of contemporary species. 

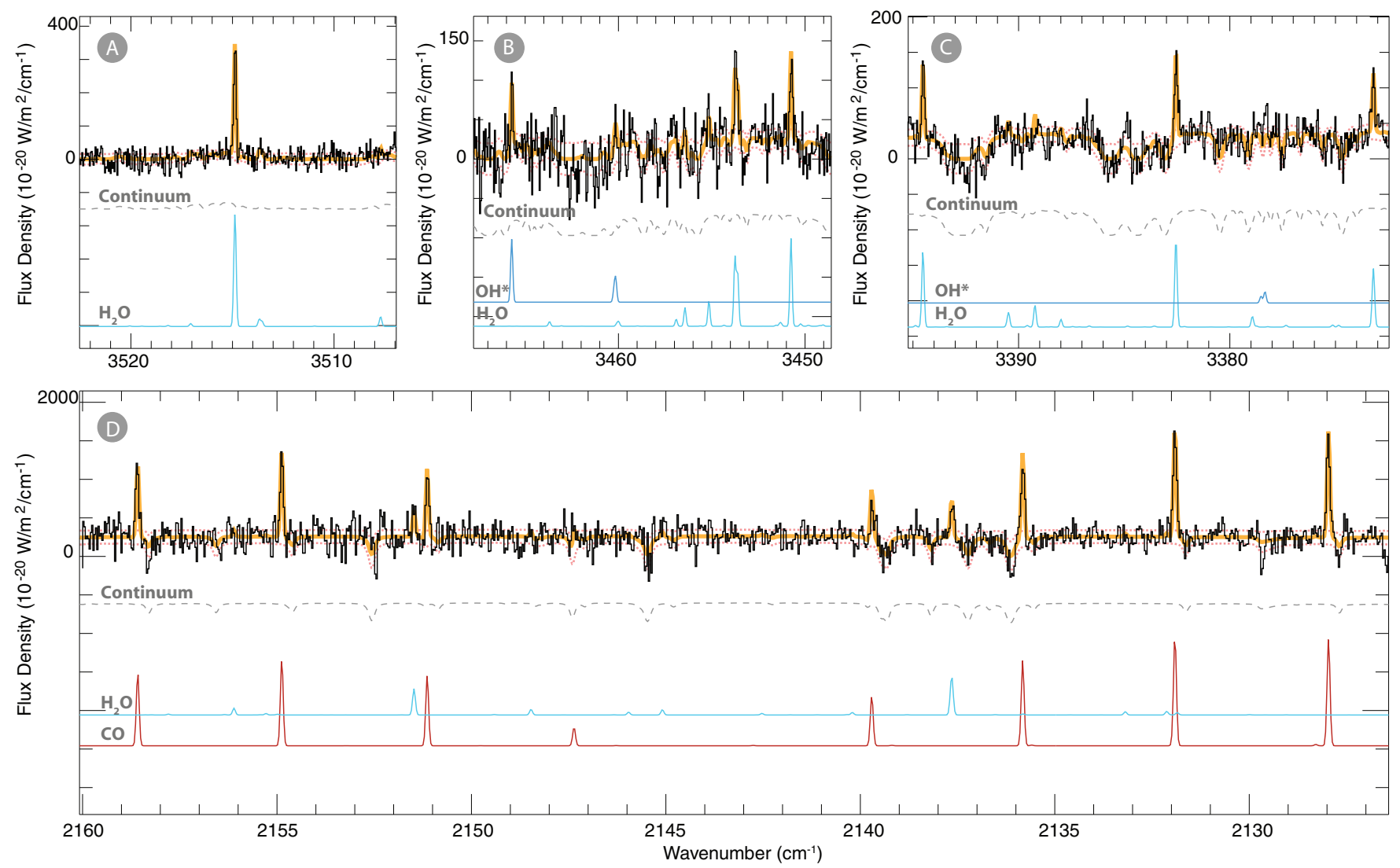

Figure 1. Detections of $\mathrm{H}_{2} \mathrm{O}$ and $\mathrm{CO}$ with NIRSPEC, extracted by summing nine spatial pixels sampling 1".78 (i.e., $\sim 1100 \mathrm{~km}$ on October 22 and $\sim 660 \mathrm{~km}$ on November 7) along the slit and centered about the nucleus. ((A)-(C)) Detection of (hot-band) water emission and OH* lines on October 22. (D) Detection of eight (R3, R2, R1, R0, P1, P2, P3, P4) strong CO lines along with two lines of $\mathrm{H}_{2} \mathrm{O}$ on October 24. Here and in Figure 2, the orange lines underlying the spectra are the sum of spectra synthesized for the molecular emissions and the continuum.

(A color version of this figure is available in the online journal.)

Figure 3(B)). Although the four volatiles $\left(\mathrm{H}_{2} \mathrm{O}, \mathrm{CH}_{4}, \mathrm{C}_{2} \mathrm{H}_{6}\right.$, and $\mathrm{HCN}$ ) displayed clear absolute increases in production rate, only $\mathrm{C}_{2} \mathrm{H}_{6}$ and $\mathrm{CH}_{4}$ showed (at most, slight) enhancements in their abundances (relative to water), and only on October 25 and 27, while that of $\mathrm{HCN}$ remained fairly constant (i.e., data agree within $1 \sigma$; see Figure $3(\mathrm{C})$ ).

With their lower sublimation temperatures, the increased abundance ratios for $\mathrm{C}_{2} \mathrm{H}_{6}$ and $\mathrm{CH}_{4}$ could perhaps be associated with a possible outburst triggered by another hypervolatile (e.g., $\mathrm{CO}$ or $\mathrm{CO}_{2}$ ). On previous dates we found $\mathrm{CO}$ to be enriched, suggesting that its production rate could vary on short timescales if it was mixed non-uniformly in the nucleus. However, the lack of simultaneous observations of $\mathrm{CO}$ (with $\mathrm{C}_{2} \mathrm{H}_{6}$ and $\mathrm{CH}_{4}$ ) precludes any conclusions on this possibility, and also on the distribution of $\mathrm{CO}$ in the nucleus. Nucleus rotation and associated variations in insolation of distinct active regions could introduce such variations, if such regions are compositionally distinct.

Finally, we obtained an ortho-para ratio (OPR) for $\mathrm{H}_{2} \mathrm{O}$ on October 22 using two instrument settings that spanned $3370-3520 \mathrm{~cm}^{-1}$. The intensities of 15 ortho- $\mathrm{H}_{2} \mathrm{O}$ and 6 para$\mathrm{H}_{2} \mathrm{O}$ lines yielded an OPR of $3.01 \pm 0.49$, restricting the spin temperature to $T_{\text {spin }} \geqslant 29 \mathrm{~K}$ (at the $1 \sigma$ level).

\subsection{Relative Abundances}

Our observations of comet C/2013 R1 yielded absolute production rates for nine primary volatiles. Since water is observed simultaneously with each trace species, we obtained highly robust abundance ratios for seven trace volatiles (and upper limits for two additional species). The individual abundance ratios (with respect to $\mathrm{H}_{2} \mathrm{O}$ ) for $\mathrm{HCN}, \mathrm{C}_{2} \mathrm{H}_{6}$, and $\mathrm{CH}_{4}$ remained largely in agreement (within $1 \sigma$; Figure $3(\mathrm{C})$ ) with their weighted mean values, despite the observed pronounced increase in gas production rates with decreasing $R_{h}$ (Figure 3(B)). This suggests constant bulk volatile composition, regardless of variations in local activity (whether or not associated with nucleus rotation) during our observing campaign.

\subsection{Spatial Profiles}

We centered the slit on the comet and aligned it along the Sun-comet direction (Figure 4). From October 22 to November 7, the phase angle (i.e., the observer-comet-Sun angle) ranged between $46^{\circ}$ and $58^{\circ}$. A viewing geometry with phase angle of $90^{\circ}$ and the slit oriented along the Sun-comet direction would be "optimal," since all pixels at positive distances along the slit from the comet's center would sample the sunward hemisphere and all negative distances the anti-sunward hemisphere. Keeping this difference in mind, we will refer to the positive distances in Figure 4 as the projected "sunward" position, and negative distances as "anti-sunward" position.

We obtained spatial profiles for the continuum and for six parent volatiles $\left(\mathrm{H}_{2} \mathrm{O}, \mathrm{CO}, \mathrm{CH}_{4}, \mathrm{HCN}, \mathrm{C}_{2} \mathrm{H}_{6}\right.$, and $\left.\mathrm{CH}_{3} \mathrm{OH}\right)$-some of them on multiple dates. On October 22, ethane displayed sunward enhancements (to projected nucleocentric distance 


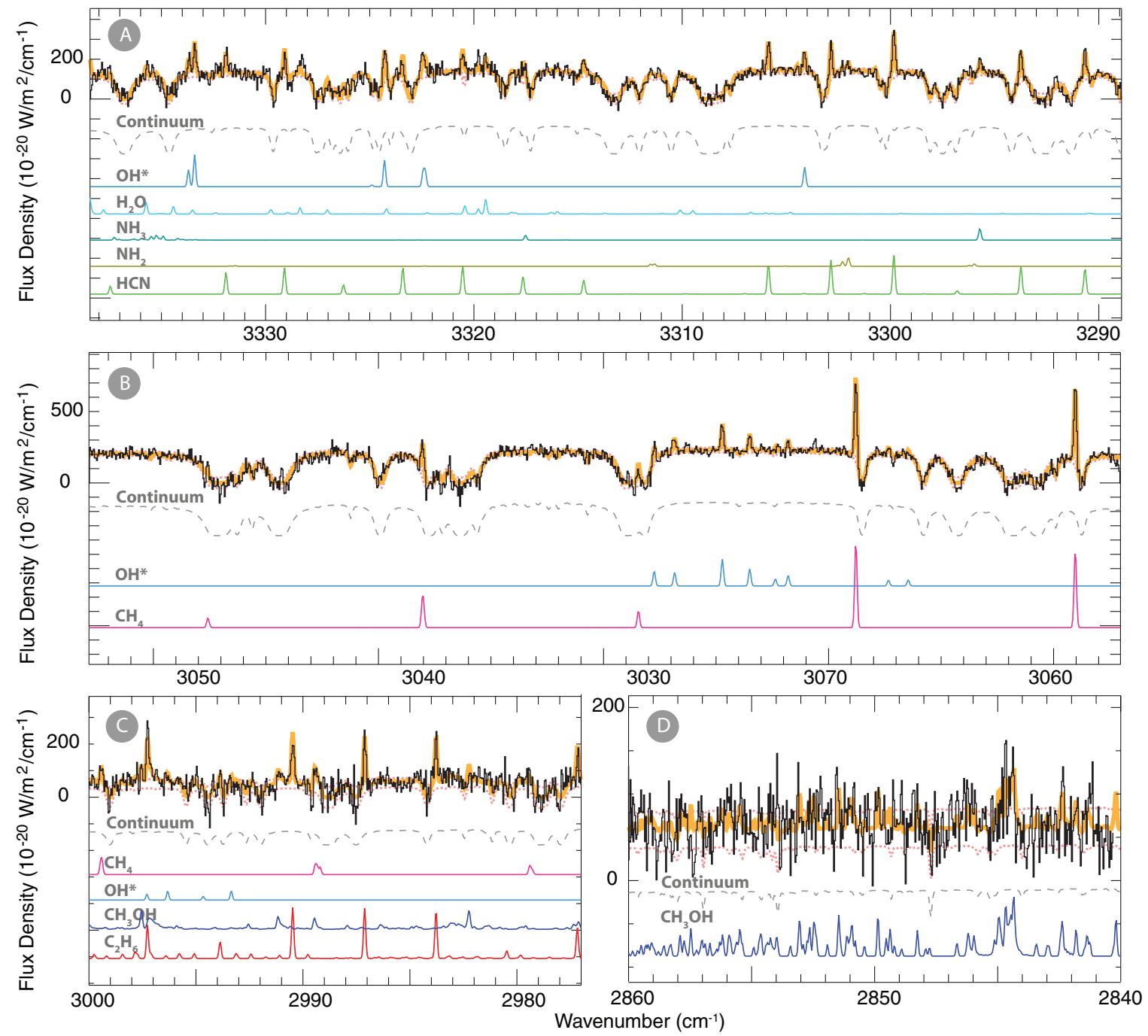

Figure 2. Detections of continuum and minor volatile species in $\mathrm{C} / 2013 \mathrm{R} 1$ (Lovejoy), along with $\mathrm{H}_{2} \mathrm{O}$ (or $\mathrm{OH}^{*}$, its direct proxy), extracted as in Figure 1. (A) $\mathrm{HCN}$, $\mathrm{NH}_{2}, \mathrm{OH}^{*}, \mathrm{H}_{2} \mathrm{O}$, and $\mathrm{NH}_{3}$ on November 7. (B) $\mathrm{CH}_{4}$ and $\mathrm{OH}^{*}$ on November 7. (C) $\mathrm{CH}_{4}, \mathrm{C}_{2} \mathrm{H}_{6}, \mathrm{CH}_{3} \mathrm{OH}$, and $\mathrm{OH}^{*}$ on October 22. (D) $\mathrm{CH}_{3} \mathrm{OH}$ on October 22. (A color version of this figure is available in the online journal.)

2000 km), while $\mathrm{H}_{2} \mathrm{O}, \mathrm{HCN}$, and $\mathrm{CH}_{3} \mathrm{OH}$ showed symmetric profiles about the nucleus (extensions of $\mathrm{CH}_{3} \mathrm{OH}$ were measured only to $\sim \pm 1000 \mathrm{~km}$ ). The continuum, on the other hand, was enhanced in the anti-sunward direction. On October 24, our observations revealed asymmetric profiles for $\mathrm{CO}$ and the continuum, both enhanced toward the sunward side. On October 25 (when we observed an apparent increase in production rates), the spatial profiles of $\mathrm{HCN}$ and $\mathrm{H}_{2} \mathrm{O}$ were rather symmetric, while methane and the continuum favored release toward the sunward side. The behavior of methane showed similar enhancement (i.e., sunward release) on October 29 (as did $\mathrm{HCN}$ ), while $\mathrm{H}_{2} \mathrm{O}$ showed flux excess in the anti-sunward direction (as did the continuum). On November 7, $\mathrm{H}_{2} \mathrm{O}, \mathrm{HCN}$, and $\mathrm{CH}_{4}$ showed slight enhancements in the sunward hemisphere, while the continuum was symmetric.

In summary, the complexity in our observed spatial profiles does not show clear delineation of outgassing sources as, for instance, would arise from polar and apolar ice phases-as was observed in comets C/2007 W1 (Boattini), 103P/Hartley2, and C/2009 P1 (Garradd; Villanueva et al. 2011a; Mumma et al. 2011; Paganini et al. 2012b). The evolving patterns in the profiles measured for $\mathrm{C} / 2013 \mathrm{R} 1$, however, could be related to nucleus rotation or to alternative physical effects like sequential activation of multiple outgassing jets (cf. CBET 3710). Additional observations at other wavelengths could test this possibility.

\section{DISCUSSION: THE CO-RICH COMETS}

Thanks to a combination of prompt observing strategies, technical advances, and a rigorous survey, we have quantified $\mathrm{CO}, \mathrm{H}_{2} \mathrm{O}$, and other volatile species in 17 OC comets since 1996, of which four were rich in native $\mathrm{CO}$. Indeed, in comet $\mathrm{C} / 2013$ $\mathrm{R} 1$, the measured $\mathrm{CO}$ abundance $\left(\sim 10 \%\right.$, relative to $\left.\mathrm{H}_{2} \mathrm{O}\right)$ was enhanced, classifying it as a CO-rich comet - the fifth highest among the 17 comets from the ground-based IR survey.

But how common are these CO-rich comets? Are they outliers of the typical population of comets? Three other surveys (all space-based) sampled $\mathrm{CO}$ and $\mathrm{H}_{2} \mathrm{O}$ simultaneously (or nearly so) with the same beam size: the Akari IR survey $\left(\mathrm{H}_{2} \mathrm{O}\right.$ is sampled directly) and UV surveys with Hubble and the International Ultraviolet Explorer (using $\mathrm{OH}$ as the proxy for $\mathrm{H}_{2} \mathrm{O}$ ). 

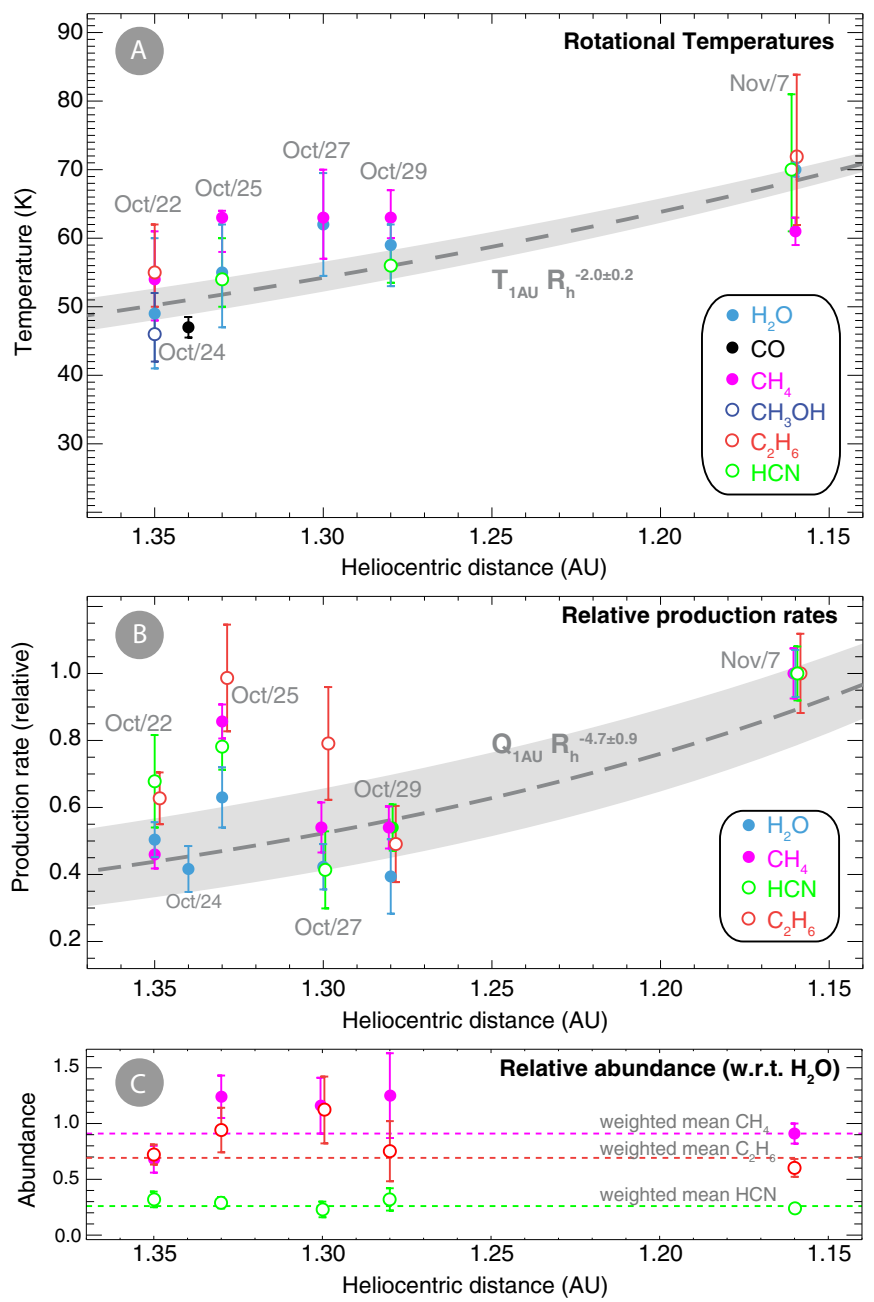

Figure 3. Temporal evolution of several key parameters in C/2013 R1 (Lovejoy), as revealed in our data. (A) Rotational temperatures retrieved for six gaseous species and their fitted trend line with heliocentric distance. (B) Individual production rates, scaled to the value obtained for each species on November 7 , and their fitted trend line. (C) Abundances for $\mathrm{CH}_{4}, \mathrm{C}_{2} \mathrm{H}_{6}$, and $\mathrm{HCN}$ (\%, relative to water) vs. heliocentric distance. The mean relative abundances were $\mathrm{HCN} /$ $\mathrm{H}_{2} \mathrm{O}=0.26 \%, \mathrm{C}_{2} \mathrm{H}_{6} / \mathrm{H}_{2} \mathrm{O}=0.69 \%$, and $\mathrm{CH}_{4} / \mathrm{H}_{2} \mathrm{O}=0.9 \%$. Some values are displaced horizontally for improved visibility, see Sections 3.1-3.3.

(A color version of this figure is available in the online journal.)

Among comets surveyed in the water-activated zone $\left(R_{h}<\right.$ $2.5 \mathrm{AU})$, Akari found that 6 of 13 comets were $\mathrm{CO}$-poor $(3 \sigma$ upper limits less than $4.3 \%$ with respect to $\mathrm{H}_{2} \mathrm{O}$ ), contrasting strongly with the fact that 11 of 13 showed significant $\mathrm{CO}_{2}$ abundance ( $>10 \%$ with respect to $\mathrm{H}_{2} \mathrm{O}$; Ootsubo et al. 2012). Of these 13 comets, only 3 were OC comets, and only C/2008 Q3 (at $R_{h}=1.8 \mathrm{AU}$ ) showed high abundance ratios for both $\mathrm{CO}$ and $\mathrm{CO}_{2},(\sim 24 \%$ and $\sim 30 \%$, respectively). Considering the large Akari aperture for the C/2008 Q3 observations (diameter of $\sim 27,000 \mathrm{~km}$ ), some fraction of the $\mathrm{CO}$ observed in it could have been produced by dissociation of precursors such as $\mathrm{CO}_{2}$, $\mathrm{H}_{2} \mathrm{CO}$, or by polymers such as polyoxymethylene (Eberhardt 1999; Fray et al. 2006). In the entire survey (at all heliocentric distances), $\mathrm{CO}$ was detected in only 3 of 18 comets sampled: C/2008 Q3 (Garradd), C/2006 W3 (Christensen) at 3.13 and 3.61 AU, and 29P/Schwassmann-Wachmann 1 at $6.18 \mathrm{AU}$. The lack of $\mathrm{CO}$ detections in most comets by the Akari survey is intriguing, although the sensitivity for $\mathrm{CO}(\sim 2 \times$ $10^{26}$ molecules $\mathrm{s}^{-1}, 3 \sigma$ detection limit) could have restricted further detections.
Figure 5 displays the $\mathrm{CO} / \mathrm{H}_{2} \mathrm{O}$ mixing ratios based on the ground-based IR survey (17 OC comets; filled circles), with the addition of (6 OC) comets for which there were no groundbased IR results (open circles). We excluded ECs to avoid any biases, such as could be produced by (possible) CO depletion after multiple perihelion passages.

While the native $\mathrm{CO}$ abundances among comets show a range from $\sim 0.3 \%$ to values of about $30 \%$ (Figure 5), OC comets having high native $\mathrm{CO}$ abundances $(>8 \%)$ seem to represent a small fraction of the sampled population. Considering a "typical" (median) abundance of $\sim 4 \%$ for CO (relative to $\mathrm{H}_{2} \mathrm{O}$ ), we arbitrarily define comets with abundances larger than twice the median $\mathrm{CO}$ abundance (i.e., $>8 \%$ ) to represent "CO-rich" comets (shaded green in Figure 5). By this standard, the only comets rich in native $\mathrm{CO}$ are $\mathrm{C} / 2001 \mathrm{Q} 4$ (NEAT), C/1995 O1 (Hale-Bopp), C/1996 B2 (Hyakutake), C/1999 T1 (McNaught-Hartley), C/2009 P1 (Garradd; that also displayed larger CO values post-perihelion (e.g., Bodewits et al. 2014)), C/2008 Q3 (Garradd), and now C/2013 R1 (Lovejoy).

Could there be evidence of chemical post-processing in some comets? A'Hearn et al. (2012) showed that the relative depletion of $\mathrm{CO}$ (in ECs and NICs) was not proportional to the reciprocal of the semi-major axis $(1 / a)$. But they found that $\mathrm{CO}_{2}$ was somewhat depleted in comets with $q<1 \mathrm{AU}$, demonstrating the possible influence of thermal modification-but other hypervolatiles (like $\mathrm{CO}, \mathrm{CH}_{4}, \mathrm{C}_{2} \mathrm{H}_{6}$ ) should then be depleted, too. The importance of $\mathrm{CO}$ is its high volatility (i.e., sensitivity to temperature), so high- $\mathrm{CO}$ comets have the potential to place important constraints on the birthplace and processing history of pre-cometary ices.

Can the relatively large $\mathrm{CO}$ content challenge and inform our current understanding of their origins? Recent mapping of the solar-nebula analog TW Hydrae with ALMA allowed estimates of the CO frost line (near 30 AU; Qi et al. 2013). Certainly, if we consider that the formation of comets occurred in the nebular mid-plane, a large $\mathrm{CO}$ abundance in these comets would support formation in cold regions near-or perhaps beyond-heliocentric distances that are consistent with the $\mathrm{CO}$ snowline. Earlier consideration of the severely depleted comet C/1999 S4 (and others) suggested formation in the Jupiter-Saturn zone where CO ice is not stable (Mumma et al. 2001a). However, the possible roles of radial mixing, shielding of certain hypervolatiles in water ice mantles, and the existence of diverse structural phases of ice, i.e., polar $\left(\mathrm{H}_{2} \mathrm{O}-\right.$ rich) and apolar (CO-rich, $\mathrm{CO}_{2}$-rich), could serve as plausible explanations for the wide dispersion of $\mathrm{CO}$ content found in comets (e.g., Paganini et al. 2012b, for a discussion). We can only expect to sharpen our conclusions and answer these questions as future observations of $\mathrm{CO}$-rich comets become available and dynamical models deal with the wide range of $\mathrm{CO}$ abundances in comets.

\section{SUMMARY}

Our NIRSPEC observations of comet C/2013 R1 resulted in detections of seven primary volatiles $\left(\mathrm{H}_{2} \mathrm{O}, \mathrm{CO}, \mathrm{CH}_{4}, \mathrm{HCN}\right.$, $\mathrm{C}_{2} \mathrm{H}_{6}, \mathrm{CH}_{3} \mathrm{OH}$, and $\left.\mathrm{NH}_{3}\right)$, upper limits for two others $\left(\mathrm{C}_{2} \mathrm{H}_{2}\right.$ and $\mathrm{H}_{2} \mathrm{CO}$ ), and detections of two product species $\left(\mathrm{OH}^{*}\right.$ and $\left.\mathrm{NH}_{2}\right)$ at pre-perihelion distances (1.35-1.16 AU) in 2013 October/ November. During this period, the measured production rate for water increased from 1.0 to $3.9 \times 10^{28}$ molecules $\mathrm{s}^{-1}$. We measured (weighted) mean abundances (\%, relative to water) for $\mathrm{CO}(9.89 \pm 2.03), \mathrm{CH}_{3} \mathrm{OH}(2.75 \pm 0.38), \mathrm{CH}_{4}(0.91 \pm 0.06)$, $\mathrm{C}_{2} \mathrm{H}_{6}(0.69 \pm 0.06), \mathrm{HCN}(0.26 \pm 0.02), \mathrm{NH}_{3}(0.10 \pm 0.02)$, 

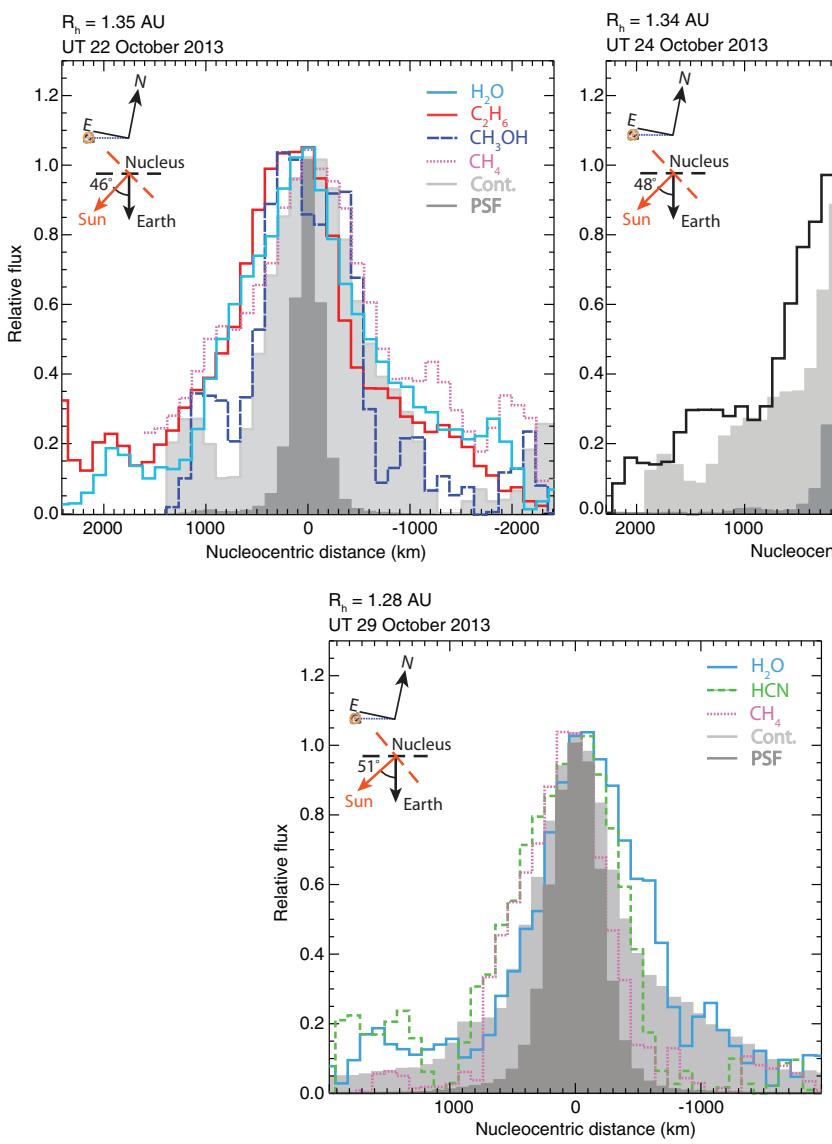
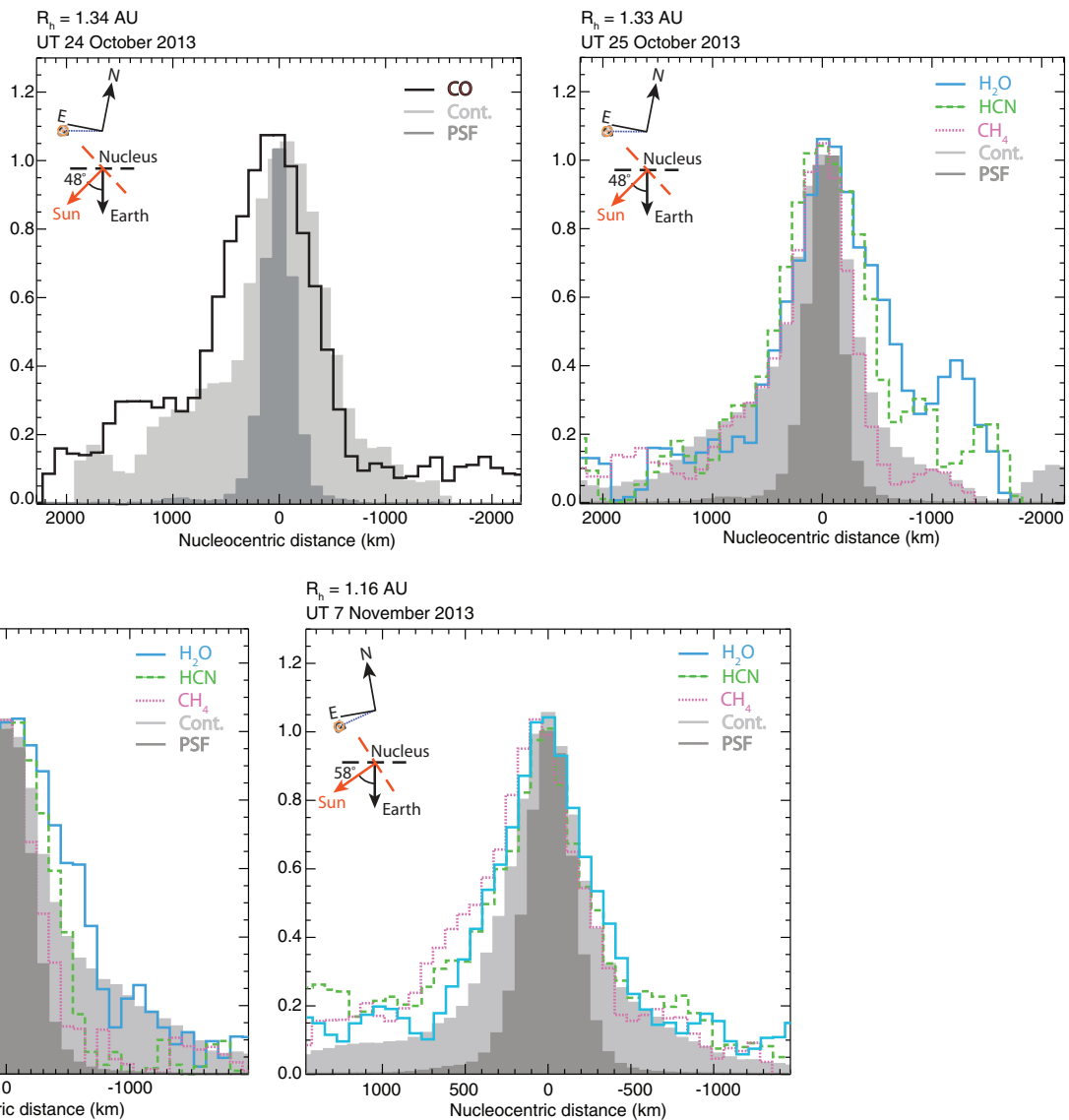

Figure 4. Spatial profiles of primary volatiles and the continuum in comet C/2013 R1 on five nights. The directions of the Sun-comet vector and solar phase angle (both are projected onto the sky plane) are indicated relative to the slit orientation, which is horizontal for these plots. The observed spatial profiles for these emissions showed complex structures, possibly tied to nucleus rotation, or multiple jets (cf. CBET 3710). Profiles are discussed in Section 3.4.

(A color version of this figure is available in the online journal.)

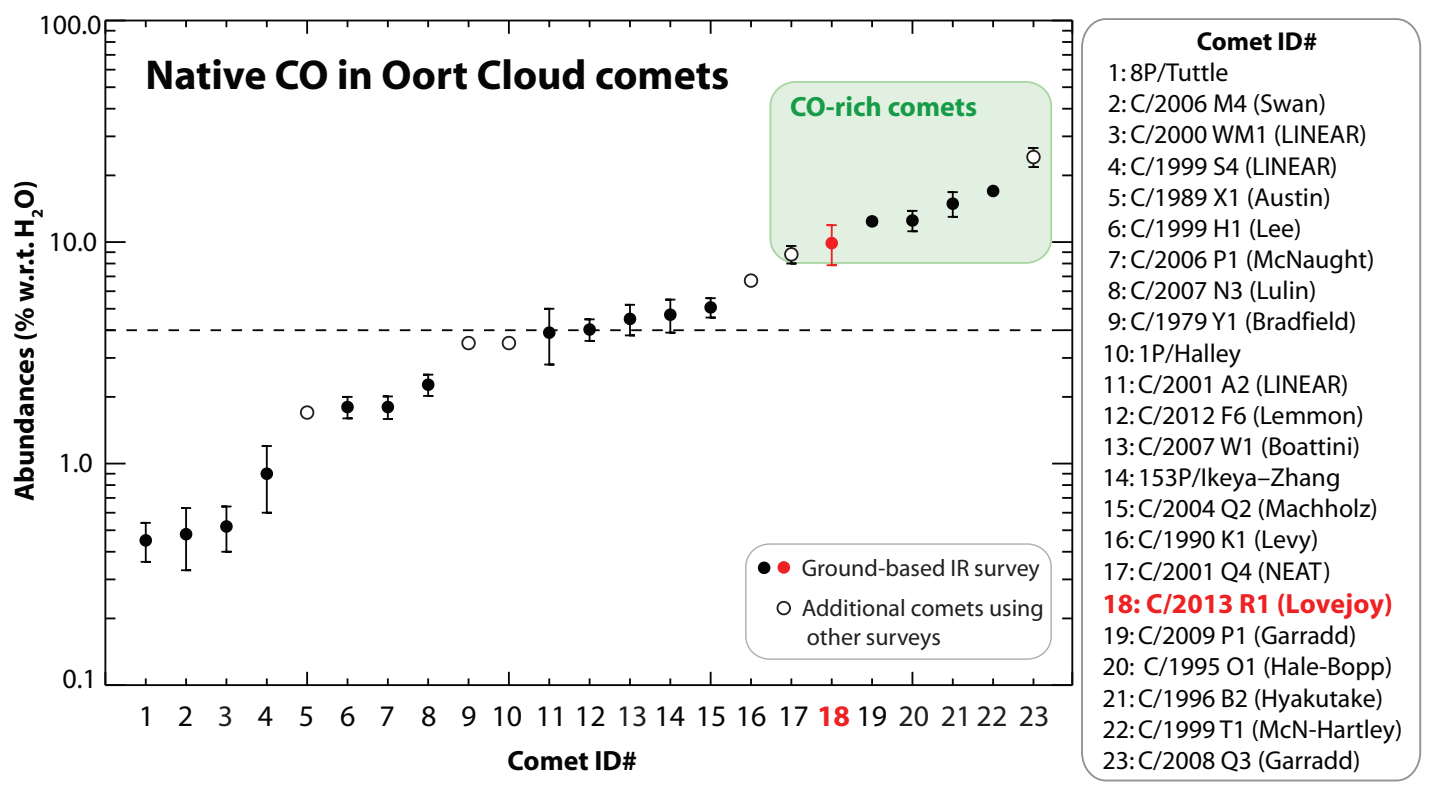

Figure 5. CO abundance ratios in Oort Cloud (OC) comets included in our IR survey. We also show results for (OC) comets C/1979 Y1, C/1989 X1, C/1990 K1, C/2001 Q4, and 1P/Halley from the UV surveys, and C/2008 Q3 from the Akari survey. For comets C/1990 K1 and C/2008 Q3, we used the weighted mean of measured $\mathrm{CO}$ abundances. The median abundance in this sample is $\sim 4 \%\left(\mathrm{CO}\right.$, relative to $\left.\mathrm{H}_{2} \mathrm{O}\right)$ and the range extends from $\sim 0.3 \%$ to $\sim 30 \%$; see Section 4 for further details. References: 1: Böhnhardt et al. (2008); 2: DiSanti et al. (2009); 3: Radeva et al. (2010); 4: Mumma et al. (2001a); 5: Feldman et al. (1997); 6: Dello Russo et al. (2009); 7: Mumma et al. (2001b); 8: Gibb et al. (2012); 9: Feldman et al. (1997); 10: Eberhardt et al. (1999); 11: Magee-Sauer et al. (2008); 12: Paganini et al. (2014); 13: Villanueva et al. (2011a); 14: DiSanti et al. (2002); 15: Bonev et al. (2009); 16: Feldman et al. (1997); 17: Lupu et al. (2007); 18: This work; 19: Paganini et al. (2012b); 20: DiSanti et al. (1999, 2001); 21: Mumma et al. (1996), DiSanti et al. (2003); 22: Mumma et al. (2003); 23: Ootsubo et al. (2012).

(A color version of this figure is available in the online journal.) 
$\mathrm{NH}_{2}(0.12 \pm 0.07), \mathrm{C}_{2} \mathrm{H}_{2}(<0.07)$, and $\mathrm{H}_{2} \mathrm{CO}(<0.06)$. We obtained consistent rotational temperatures (at the $1 \sigma-2 \sigma$ level) for six species $\left(\mathrm{H}_{2} \mathrm{O}, \mathrm{CO}, \mathrm{CH}_{4}, \mathrm{HCN}, \mathrm{C}_{2} \mathrm{H}_{6}\right.$, and $\left.\mathrm{CH}_{3} \mathrm{OH}\right)$, suggesting a common source of rotational excitation within NIRSPEC's FOV on each date. The OPR for $\mathrm{H}_{2} \mathrm{O}$ was $3.01 \pm$ 0.49 , corresponding to a spin temperature larger than $29 \mathrm{~K}$ (at the $1 \sigma$ level). Our results demonstrate a rich chemistry that, compared to most OC comets, reveals highly enriched $\mathrm{CO}$, (at most) slightly enriched $\mathrm{CH}_{3} \mathrm{OH}, \mathrm{C}_{2} \mathrm{H}_{6}$, and $\mathrm{HCN}$, and $\mathrm{CH}_{4}$ consistent with "normal," yet depleted $\mathrm{NH}_{3}, \mathrm{C}_{2} \mathrm{H}_{2}$, and $\mathrm{H}_{2} \mathrm{CO}$. $\mathrm{NH}_{2}$ was also depleted, as expected if it is the principal product of $\mathrm{NH}_{3}$ photolysis.

We have identified a new CO-rich comet. Future observations will test whether these comets stem from a larger population and, if so, assess whether the observed large CO abundance could indeed inform our understanding of the true formative conditions experienced by these icy bodies.

We gratefully acknowledge support by NASA's PAST Program (L.P., M.J.M, M.A.D., G.L.V.) and NAI through its member Teams at GSFC (M.J.M., M.A.D., B.P.B., G.A.B.) and at UH (J.V.K., K.J.M.; No. NNA09DA77A), and NSF (B.P.B., E.L.G.; Award 1211362). The data of October 24 and 25 were collected during part of the NASA Keck time awarded for observations of comet ISON, and are publicly available through the Keck Observatory Archive. We thank the anonymous referee for useful insights on this paper. The authors acknowledge the very significant cultural role and reverence that the summit of Mauna Kea has always had within the indigenous Hawaiian community. We are most fortunate to have the opportunity to conduct observations from this mountain.

\section{REFERENCES}

A'Hearn, M. F., Feaga, L. M., Keller, H. U., et al. 2012, ApJ, 758, 29

A'Hearn, M. F., Millis, R. L., Schleicher, D. G., Osip, D. J., \& Birch, P. V. 1995, Icar, 118, 223

Bergin, E. A. 2011, in Physical Processes in Circumstellar Disks around Young Stars, ed. P. J. V. Garcia (Chicago, IL: Univ. Chicago Press), 55

Biver, N., Bockelée-Morvan, D., Colom, P., et al. 1997, EM\&P, 78, 5

Biver, N., Bockelée-Morvan, D., Crovisier, J., et al. 1999, AJ, 118, 1850

Biver, N., Bockelée-Morvan, D., Crovisier, J., et al. 2006, A\&A, 449, 1255

Bockelée-Morvan, D., Bossier, J., Biver, N., \& Crovisier, J. 2010, Icar, 210, 898

Bockelée-Morvan, D., Crovisier, J., Mumma, M. J., \& Weaver, H. A. 2004, in Comets II, ed. M. C. Festou, H. U. Keller, \& H. A. Weaver (Tucson, AZ: Univ. Arizona Press), 391

Bodewits, D., Farnham, T. L., A'Hearn, M. F., et al. 2014, ApJ, 786, 48

Böhnhardt, H., Mumma, M. J., Villanueva, G. L., et al. 2008, ApJL, 683, L71

Bonev, B. P. 2005, PhD thesis. Univ. Toledo, http://astrobiology.gsfc.nasa.gov/ Bonev_thesis.pdf

Bonev, B. P., Mumma, M. J., DiSanti, M. A., et al. 2006, ApJ, 653, 774

Bonev, B. P., Mumma, M. J., Gibb, E. L., et al. 2009, ApJ, 699, 1563

Cochran, A. L., Barker, E. S., \& Gray, C. L. 2012, Icar, 218, 144

Cottin, H., \& Fray, N. 2008, SSRv, 138, 179

Crovisier, J., Encrenaz, Th., Lelloouch, E., et al. 1999, in The Universe as Seen by ISO, ed. P. Cox \& M. F. Kessler (ESA SP-427; Noordwijk: ESA), 161

Dello Russo, N., Vervack, R. J., Jr., Weaver, H. A., \& Lisse, C. M. 2009, Icar, 200,271
DiSanti, M. A., Bonev, B. P., Magee-Sauer, K., et al. 2006, ApJ, 650, 470

DiSanti, M. A., Bonev, B. P., Villanueva, G. L., \& Mumma, M. J. 2013, ApJ, 763,1

DiSanti, M. A., Dello Russo, N., Magee-Sauer., K., et al. 2002, in Proc. ACM 2002, ed. B. Warmbein (ESA SP-500; Noordwijk, Netherlands: ESA), 571

DiSanti, M. A., Mumma, M. J, Dello Russo, N., \& Magee-Sauer, K. 2001, Icar, 153,361

DiSanti, M. A., Mumma, M. J., Dello Russo, N., Magee-Sauer, K., \& Griep, D. M. 2003, JGR, 108, 5061

DiSanti, M. A., Mumma, M. J., Dello Russo, N., et al. 1999, Natur, 399, 662

DiSanti, M. A., Villanueva, G. L., Milam, S. N., et al. 2009, Icar, 203, 589

Eberhardt, P. 1999, SSRv, 90, 45

Evans, N. J., II, Dunham, M. M., Jørgensen, J. K., et al. 2009, ApJS, 181, 321

Feaga, L. M., A'Hearn, M. F., Farnham, T. L., et al. 2013, AJ, 147, 24

Feldman, P. D., Cochran, A. L., \& Combi, M. R. 2004, in Comets II, ed. M. C. Festou, H. U. Keller, \& H. A. Weaver (Tucson, AZ: Univ. Arizona Press), 425

Feldman, P. D., Festou, M. C., Tozzi, G.-P., \& Weaver, H. A. 1997, ApJ, 475,829

Fink, U. 2009, Icar, 201, 311

Fowler, A. 1910, MNRAS, 79, 176 (ibid. 484)

Fowler, A. 1912, ApJ, 35, 85

Fray, N., Bénilan, Y., Biver, N., et al. 2006, Icar, 184, 239

Gibb, E. L., Bonev, B. P., Villanueva, et al. 2012, ApJ, 750, 102

Gibb, E. L., Mumma, M. J., Dello Russo, N., DiSanti, M. A., \& Magee-Sauer, K. 2003, Icar, 165, 391

Hergenrother, C. W., Wyatt, C., Yoshida, S., et al. 2013, CBET, 3710, 1

Kawakita, H., \& Mumma, M. J. 2011, ApJ, 727, 91

Lippi, M., Villanueva, G. L., DiSanti, M. A., et al. 2013, A\&A, 551, A51

Lupu, R. E., Feldman, P. D., Weaver, H. A., \& Tozzi, G. P. 2007, ApJ, 670, 1473

Magee-Sauer, K., Mumma, M. J., DiSanti, M. A., et al. 2008, Icar, 194, 347

Mumma, M. J., Bonev, B. P., Villanueva, G. L., et al. 2011, ApJL, 734, L7

Mumma, M. J., \& Charnley, S.B. 2011, ARA\&A, 49, 471

Mumma, M. J., Dello Russo, N., DiSanti, M. A., et al. 2001a, Sci, 292, 1334

Mumma, M. J., DiSanti, M. A., Dello Russo, N., et al. 1996, Sci, 272, 1310

Mumma, M. J., DiSanti, M. A., Dello Russo, N., et al. 2003, AdSpR, 31, 2563

Mumma, M. J., McLean, I. S., DiSanti, M. A., Larkin, J. E., \& Dello Russo, N. 2001b, ApJ, 546, 1183

Nakano, S. 2013, C/2013 R1 (Lovejoy), in Nakano Note NK 2585, http://www.oaa.gr.jp/ oaacs/nk/nk2585.htm

Ootsubo, T., Kawakita, H., Hamada, S., et al. 2012, ApJ, 752, 15

Ootsubo, T., Watanabe, J., Kawakita, H., Honda, M., \& Furusho, R. 2007, P\&SS, 55,1044

Paganini, L., Mumma, M. J., Boehnhardt, H., et al. 2013, ApJ, 766, 100

Paganini, L., Mumma, M. J., Bonev, B. P., et al. 2012a, Icar, 218, 644

Paganini, L., Mumma, M. J., Villanueva, G. L., et al. 2012b, ApJL, 748, L13

Paganini, L., Mumma, M. J., Villanueva, G. L., et al. 2014, AJ, 147, 15

Pluvinel, C. B., \& Baldet, F. 1911, ApJ, 34, 89

Qi, C., Öberg, K. I., Wilner, D. J., et al. 2013, Sci, 341, 630

Radeva, Y. L., Mumma, M. J., Bonev, B. P., et al. 2010, Icar, 206, 764

Radeva, Y. L., Mumma, M. J., Villanueva, G. L., \& A'Hearn, M. F. 2011, ApJ, 729,135

Stern, A. S. 2003, Natur, 424, 639

van Dishoeck, E. F., \& Blake, G. A. 1998, ARA\&A, 36, 317

van Dishoeck, E. F., \& Hogerheijde, M. R. 1999, in The Origin of Stars and Planetary Systems, ed. C. J. Lada \& N. D. Kylafis (Dordrecht: Kluwer), 97

Villanueva, G. L., DiSanti, M. A., Mumma, M. J., \& Xu, L.-H. 2012a, ApJ, 747,37

Villanueva, G. L., Magee-Sauer, K., \& Mumma, M. J. 2013, JQSRT, 129, 158

Villanueva, G. L., Mumma, M. J., Bonev, B. P., et al. 2012b, JQSRT, 113, 202

Villanueva, G. L., Mumma, M. J., DiSanti, M. A., et al. 2011a, Icar, 216, 227

Villanueva, G. L., Mumma, M. J., \& Magee-Sauer, K. 2011b, JGRE, 116, 08012

Weaver, H. A., Feldman, P. D., McPhate, J. B., et al. 1994, ApJ, 422, 374

Wooden, D. H., Harker, D. E., Woodward, C. E., et al. 1997, ApJ, 517, 1034

Zolensky, M. E., Zega, T. J., Yano, H., et al. 2006, Sci, 314, 1735 